\title{
Environmental flow assessment in estuaries taking into consideration species dispersal in fragmented potential habitats
}

\author{
Heyue Zhang, Tao Sun*, SuFeng Xue, Wei Yang, Xinan Yin \\ State Key Laboratory of Water Environment Simulation, School of Environment, Beijing Normal University, Beijing 100875, China
}

\section{A R T I C L E I N F O}

\section{Article history:}

Received 25 November 2016

Received in revised form 21 March 2017

Accepted 22 March 2017

\section{Keywords:}

Environmental flow assessment

Estuary

Species dispersal

Individual-based model

Yangtze River Estuary

\begin{abstract}
A B S T R A C T
Here, we propose an approach to environmental flow assessment that pays attention to species dispersal among fragmented potential habitat patches affected by river inflow and tidal currents in estuaries. The approach consists of three steps. In step one, potential suitable habitats were mapped and the Habitat Aggregation Index (HAI) was determined to understand the fragmentation of potential suitable habitats by integrating the requirements for critical environmental factors that have temporal and spatial variability. In the second step, an individual-based model was developed to simulate the dispersal of target species among potential habitat patches. The model provided the species distributions for altered hydrological processes. In the third step, environmental flows were defined by comparing the occupancy of suitable habitat patches by individual organisms and habitat aggregation for varying freshwater inflows. This approach was tested using a case study in the Yangtze River Estuary. We stressed the ecological importance of flood pulse, rather than average discharge, and recommend a Gaussian-type flood pulse, as provides a win-win point for both the numbers of individuals that could occupy suitable habitat and the HAI. We also demonstrated the importance of the peak flow and flood pulse duration in terms of affecting species distribution. Based on the results presented here, the proposed approach offers a flexible assessment of environmental flow for aquatic ecosystems.
\end{abstract}

(c) 2017 Elsevier Ltd. All rights reserved.

\section{Introduction}

Estuaries and coasts are important transitional environments connecting the land to the sea. They have high ecological and biodiversity functional values, as well as diverse cultural and economic values (Roy et al., 2001; Lotze et al., 2006; Piehler and Smyth, 2011; Brush et al., 2016). Freshwater inflow can serve a variety of important functions through maintenance of salinity gradients, sediment and nutrient transport, and provision of habitats for estuarine species (Crump et al., 2004; Lamberth et al., 2009; Valdemarsen et al., 2015). However, both climate change and intense regulation of water resources has significantly altered the natural flow regimes of rivers worldwide (Döll et al., 2009; Yang et al., 2015), and thus has negatively affected their hydrodynamic processes, environmental gradients, and species distributions, particularly in the case of estuaries (Bianchi and Allison, 2009; Allison and Meselhe, 2010; Korus and Fielding, 2015; Liu et al., 2016). In order to define the quantity, quality, and time required to maintain water use balance between human activities and ecosystems in

\footnotetext{
* Corresponding author.

E-mail address: suntao@bnu.edu.cn (T. Sun).
}

estuaries, environmental flow assessments have been undertaken. These assessments are important tools for informing ecosystem restoration, water resource management, and reservoir management (Tharme, 2003; Yang et al., 2009; Walsh et al., 2013; Cruzeiro et al., 2016).

A critical issue in environmental flow assessment is the understanding of ecological responses to hydrological alterations. By considering the complex interactions between ecological and hydrological processes, habitat simulation models can quantitatively analyze the ecological effects of hydrological processes through a contrasting relationship between freshwater inflow and environmental factors that are critical to restricting suitable habitats, and hence have been widely used in estuarine environmental flow assessments (Jassby et al., 1995; Tharme, 2003; Li et al., 2009; Sun et al., 2013, 2015). Despite this, many major stressors in estuarine and coastal ecosystems can result in either decreased suitable habitat area or habitat fragmentation (Thrush et al., 2008; Zhang et al., 2016; Lefcheck et al., 2016). Habitat fragmentation has been recognized as a major threat to terrestrial and marine ecosystems (Young et al., 1996; Fahrig, 2003; Lindenmayer and Fischer, 2013; Zhang et al., 2016). Increased habitat fragmentation reduces connectivity among habitat patches, obstructs species diffusion, reduces established populations, hinders species dispersal 


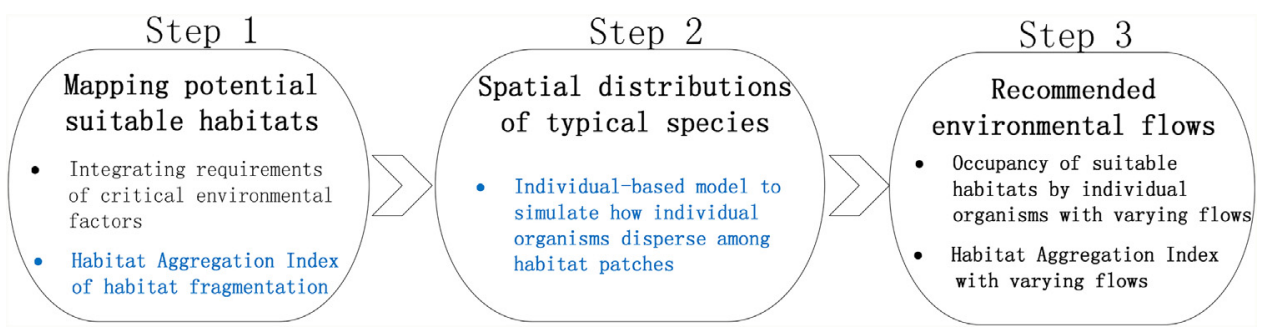

Fig. 1. Approach for environmental flow assessments in estuaries.

and migration activities (Bierregaardet et al., 1992; Elgar and Clode, 2001; Layman et al., 2004), and has a direct impact on species distribution and biogenetic structure. Habitat simulation models focus on potential habitats for species in altered freshwater inflows. Nevertheless, individual organisms frequently move among complex landscapes (Dover and Settele, 2009; Rabinowitz and Zeller, 2010), and even among fragmented habitat patches (Antongiovanni and Metzger, 2005; Lees and Peres, 2009; Dorchin et al., 2013).

The adaptation of individual behaviors under stress caused by the fragmentation of potential suitable habitats has seldom been included in environmental flow assessments. Rather than defining environmental flows based on potential suitable habitats, the present study focused on species distribution in fragmented estuarine habitat patches with hydrological alteration. In particular, an individual-based model was built to simulate how target organisms disperse individually among fragmented habitat patches. The dispersal preferences were defined using the suitability and spatial distribution of potential habitat patches under the action of different river flows and tidal currents, which were mapped through a suitable habitat evaluation model based on the fuzzy logic method.

\section{Methods}

\subsection{Mapping potential habitat distributions}

To define environmental flows in estuaries with complex eco-hydrological processes, here we propose an approach to environmental flow assessment based on species spatial distributions, taking into consideration of their dispersal among potential habitat patches with alterations in freshwater inflow. The approach consists of three steps (Fig. 1). In the first step, potential suitable habitat was mapped and the Habitat Aggregation Index (HAI) was used to understand the fragmentation of potential suitable habitats based on the integration of critical environmental factors that have temporal and spatial variability. In the second step, an individualbased model was developed to simulate the dispersal of target species among potential habitat patches. The species distribution with altered hydrological processes was obtained from this model. In the third step, environmental flows in estuaries were compared for varying freshwater inflows based on the occupancy rates for suitable habitat patches by individual organisms and the HAIs.

In estuaries, habitats that are utilized during the breeding and growth seasons for typical migratory species are usually located in shallow water. Water depth and water salinity for typical migratory species during pivotal life-stages (e.g., reproduction and juvenile growth) are usually selected to indicate habitat suitability for species in estuaries (Kurup et al., 1998; Koch, 2001; Robins et al., 2005; Poff and Zimmerman, 2010; Sun et al., 2015). In addition, fluctuations in water salinity that are affected by the combined action of freshwater and seawater have important impacts on aquatic organisms (Wang, 2012), especially on larvae survival (Cheng, 1997). Proper salinity fluctuation can stimulate aquatic organisms to spawn, although aquatic organisms can also suffer extensive mortality rates due to instantaneous variations in water salinity
(Browne and Wanigasekera, 2000; Calliari et al., 2008). Accordingly, in this study, we selected water depth, water salinity, and water salinity fluctuation rates as the critical environmental factors required for mapping suitable habitats for target species. Salinity fluctuation rates were calculated based on the temporal variation in salinity, which can be expressed as a standard deviation formula:

$F=\sqrt{\frac{1}{N} \Sigma_{i=1}^{N}\left(x_{i}-\frac{1}{N} \Sigma_{i=1}^{N} x_{i}\right)^{2}}$

where $x_{i}$ represents salinity at moment $i$, and $N$ represents the tidal fluctuation time. The standard deviation reflects the data set dispersion measures, so that within the same time frame, a higher fluctuation rate value reflects a more intense salinity fluctuation.

Temporal and spatial variations in water depth and salinity can be simulated as a combined function of river discharge and tidal currents using hydrodynamic and water quality models. The responses of target environmental factors to changes in river discharge were thus quantified and the salinity fluctuation rates calculated at different locations. The Environmental Fluid Dynamics Code (EFDC), which has been adopted by many researchers as a simulation tool, was applied to simulate the space-time distribution of environmental factors (Liu et al., 2008; Seo and Ahn, 2012; Kang et al., 2015). Based on the simulated distributions of water depth, salinity, and salinity fluctuation rate in the estuary, the suitability of habitats at different locations for target species could be defined by integrating the different requirements for the environmental factors using the fuzzy logic method. The suitability of each habitat was classified using the Habitat Suitability Index (HSI) with four degrees of suitability (0-0.25 for very unsuitable, $0.25-0.5$ for unsuitable, $0.5-0.75$ for suitable, $0.75-1$ for very suitable). Additionally, the HAI was adopted to investigate the fragmentation of potential suitable habitats (Xue et al., 2016).

\subsection{Spatial distributions of typical species by the individual-based model}

An individual-based model was built through the application of cellular automata (CA) to simulate the dispersal of individual organisms among habitat patches. The spatial distribution of species with hydrological alteration was obtained from the model. The modeling space was divided into several two-dimensional square cells, and each cell was composed of three elements: habitat suitability $(H S I)$, number of individual organisms $(S)$, and carrying capacity $\left(K, K=K_{\max }{ }^{*} H S I\right)$. The state of a certain cell at time $(t)$ was decided by both its original state and the state of neighborhood at time ( $t$ 1). Cells with different states transformed based on the same rules in divergent space and time. Rules for individual dispersion were determined by the dispersal rate, dispersal direction, and dispersal quantity for each cell (Fig. 2).

\subsubsection{Density-dependent dispersal rate}

The influence of individual density on the dispersal rate depends on the relationships between individuals. Density negatively affects dispersal when individuals being aggregation to against predators, 


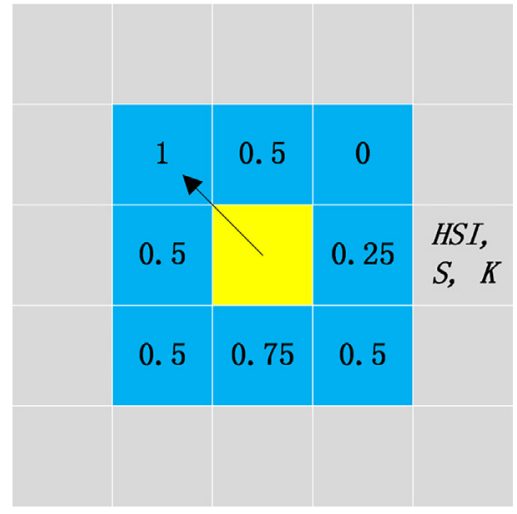

Fig. 2. Individual-based model.

but positively when individuals compete for resources. To calculate the dispersal rate of each cell, we applied a commonly used densitydependent dispersal equation (Bocedi et al., 2014):

$d_{\left(c_{i}, t\right)}=D_{0} /\left[1+e^{-}\left(s_{\left(c_{i}, t-1\right)} / K_{C_{i}}-\beta\right) \alpha\right]$

where $C_{i}$ represents cell $i, D_{0}$ represents the maximum value of the dispersal rate, $\beta$ denotes the inflection point of the dispersal curve, and $\alpha$ denotes the slope at the inflection point.

The values of $\alpha$ and $\beta$ can control the transformation of density that negatively affects dispersal to density that positively affects dispersal. In this study, such transformations occurred when $S_{\left(C_{i}, t-1\right)} / K_{C_{i}}>0.3, D_{0}=0.6, \alpha=6$, and $\beta=1$, or when $S_{\left(C_{i}, t-1\right)} / K_{C_{i}} \leq 0.3, D_{0}=0.2$, and $\alpha=-10, \beta=0.005$ (Kun and Scheuring, 2006).

\subsubsection{Dispersal direction}

Species have different perceptual ranges within the environment according to the species characteristics. We assumed that individuals in each cell could perceive the eight neighboring cells, and that they would disperse toward cells that have high HSI.

\subsubsection{Dispersal quantity}

The individual numbers in $C_{i}$ at time $(t)$ can be expressed as:

$S_{\left(c_{i}, t\right)}=S_{\left(c_{i}, t-1\right)}+I_{\left(c_{i}, t-1\right)}-E_{\left(c_{i}, t-1\right)}$

where $S_{(C i, t)}$ represents the individual numbers in $C_{i}$ at time $(t)$, $S_{(C i, t-1)}$ represents the individual numbers in $C_{i}$ at time $(t-1), I_{(C i, t-1)}$ represents the numbers of individuals that move into $C_{i}$ from the surrounding eight cells at time $(t-1)$, and $E_{(C i, t-1)}$ represents the number of individuals that move out from $C_{i}$.

$E_{\left(c_{i}, t-1\right)}=S_{\left(c_{i}, t-2\right)} d_{\left(c_{i}, t-1\right)}$

where $d_{(C i, t-1)}$ represents the dispersal rate in $C_{i}$ at time $(t-1)$.

$I_{\left(c_{i}, t-1\right)}=\Sigma_{j=1}^{N\left(c_{i}\right)}\left(\frac{H S I\left(c_{i}\right)}{\sum_{k=1}^{N\left(c_{j}\right)} H S I\left(c_{k}\right)} E_{\left(c_{j}, t-1\right)}\right)$

where $N_{(C i)}$ represents the number of individual in the neighbors $\left(C_{j}\right)$ of $C_{i}$, and $N_{\left(C_{j}\right)}$ represents the number of individuals in the neighbors $\left(C_{k}\right)$ of $C_{j}$. The value of $I_{(C i, t-1)}$ is decided using the proportion of HSI in $C_{i}$ account for HSI in $C_{k}$.

\section{Case study}

The Yangtze River Estuary is located on the central eastern coast of China, and is one of the largest estuaries in the world. The Yangtze River Estuary is a broad, funnel-shaped deltaic channel that is more than $50 \mathrm{~km}$ at its mouth. From Xuliujing, the estuary is divided
Table 1

Environmental factor requirements for Chinese mitten crabs.

\begin{tabular}{llll}
\hline Environmental factor & Minimum & Most Suitable & Maximum \\
\hline Salinity (ppt) & 3 & 10 & 18 \\
Depth (m) & 2 & 6 & 10 \\
Fluctuation rate & 0 & 3 & 16 \\
\hline
\end{tabular}

into north and south branches, and the south branch is then further divided into south and north passages at Jiuduansha (Fig. 3). The Yangtze River is an ecologically sensitive area in which altered freshwater inflow can significantly affect relevant environmental factors, altering the spawn sites and annual catches of fish (Duan et al., 2009; Xu et al., 2013).

Natural floods are essential to guard against the adverse impacts of longtime uniform discharges on the growth and reproduction of aquatic organisms (Lytle and Poff, 2004). In the short-term, intense freshwater flooding can lead to a massive amount of freshwater replacement, stochastically changing the hydrological connectivity and forming a highly heterogeneous habitat (Heiler et al., 1995; Pringle, 2001; Gallardo et al., 2008). The Three Gorges Project that began in 2003 has dramatically altered the annual distribution of freshwater inflow to the Yangtze River Estuary through river discharge control and water storage (Mueller et al., 2008; Guo et al., 2012). Implementation of the Three Gorges Project reduced the peak flow while altering the pulse mode and duration of natural floods (Tullos, 2009). Accordingly, we defined six types of freshwater pulse with various pulse durations and peak flows based on the flow data for Xuliujing during 2000-2012. The total flows were consistent. Extreme cases for constant flows were also considered (Fig. 4).

In the study region, the Chinese mitten crab (Eriocheir sinensis), which primarily spawns in the Yangtze River Estuary during March to June, was selected as a representative species. Water depth, salinity, and fluctuation rate requirements for healthy biological processes of the Chinese mitten crab are shown in Table 1 (Rudnick et al., 2005; Barnes et al., 2006; Inglis et al., 2006).

\section{Results}

The calculated tidal heights, velocities, flow directions, and salinities were previously verified using field data in the Yangtze River Estuary (Xue et al., 2016). The model performance confirmed that simulation results were congruent with the observed data.

Different combinations of freshwater pulse type (shown in Fig. 4) and tidal current were defined as the boundary conditions in the validated model to simulate the distributions of environmental factors with varying types of freshwater pulse. The HSI (Habitat Suitability Index) could be subsequently determined for different locations in the estuary. Fig. 5 illustrates variations in suitable salinity area (3-18 ppt) and potential suitable habitat area (HSI $>0.5$ ) for Chinese mitten crabs in different types of freshwater pulse. Based on results in Fig. 5, we discovered that the largest area with suitable salinity for Chinese mitten crabs occurred in a constant flow of $7000 \mathrm{~m}^{3} / \mathrm{s}$ (CF1). However, the largest suitable habitat area occurred with a Gaussian pulse from 7000 to $45,000 \mathrm{~m}^{3} / \mathrm{s}$ that lasts two months with a releasing rate of $1500 \mathrm{~m}^{3} / \mathrm{s} /$ day (GP1).

A total of $3 \times 10^{5}$ individuals were set in the upstream Yangtze River Estuary in the individual-based model. Based on the dispersal rules given above, the distribution of Chinese mitten crabs in different habitat patches could be obtained. Fig. 6 presents the relationship between the number of individuals that could occupy suitable habitat patches and the HAI with varying types of freshwater pulse. Based on the results in Fig. 6, we recommend that GP1 should be maintained to satisfy the highest level of occupancy of suitable habitat patches by individual organisms and to improve 


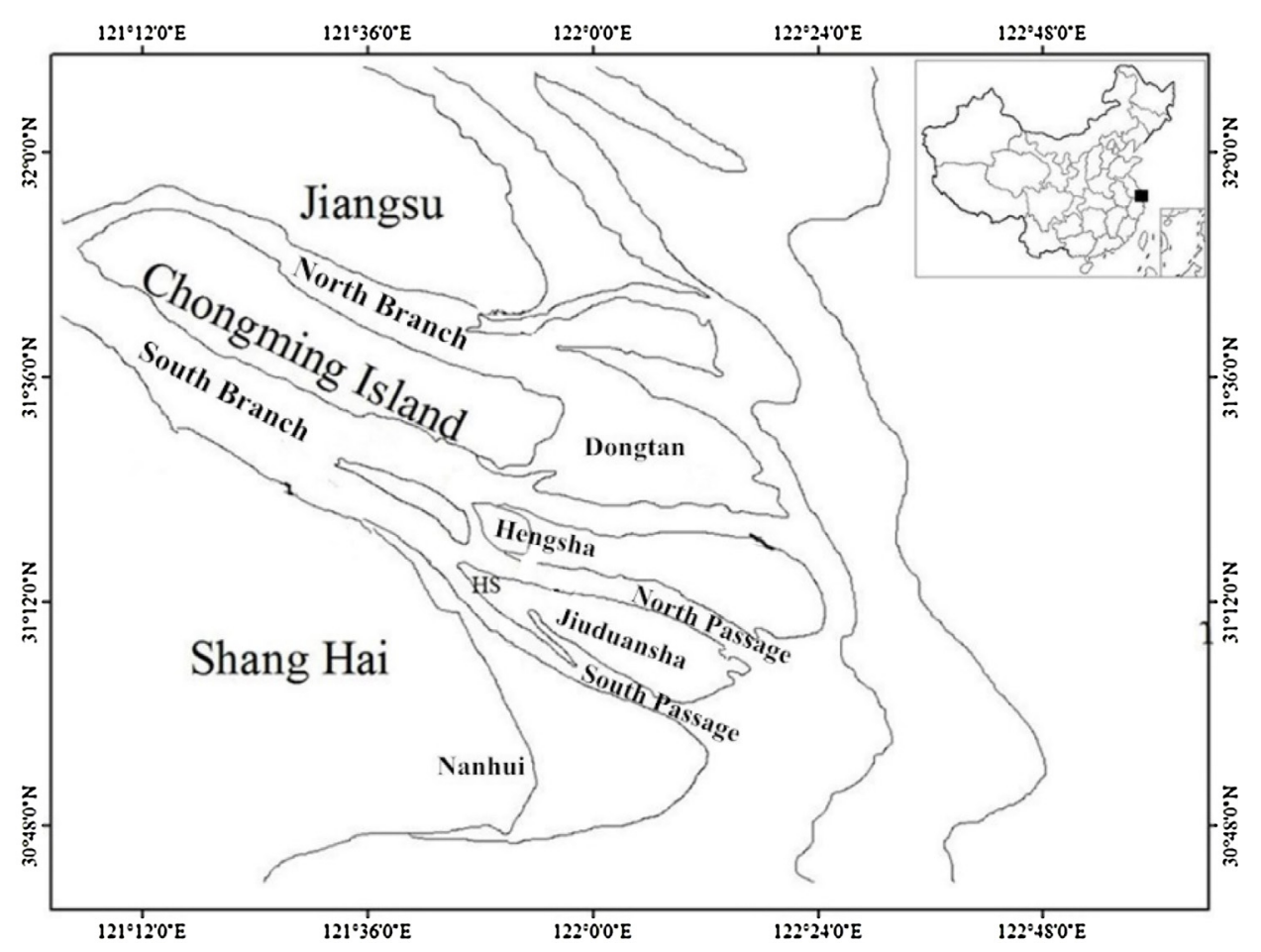

Fig. 3. Yangtze River Estuary.

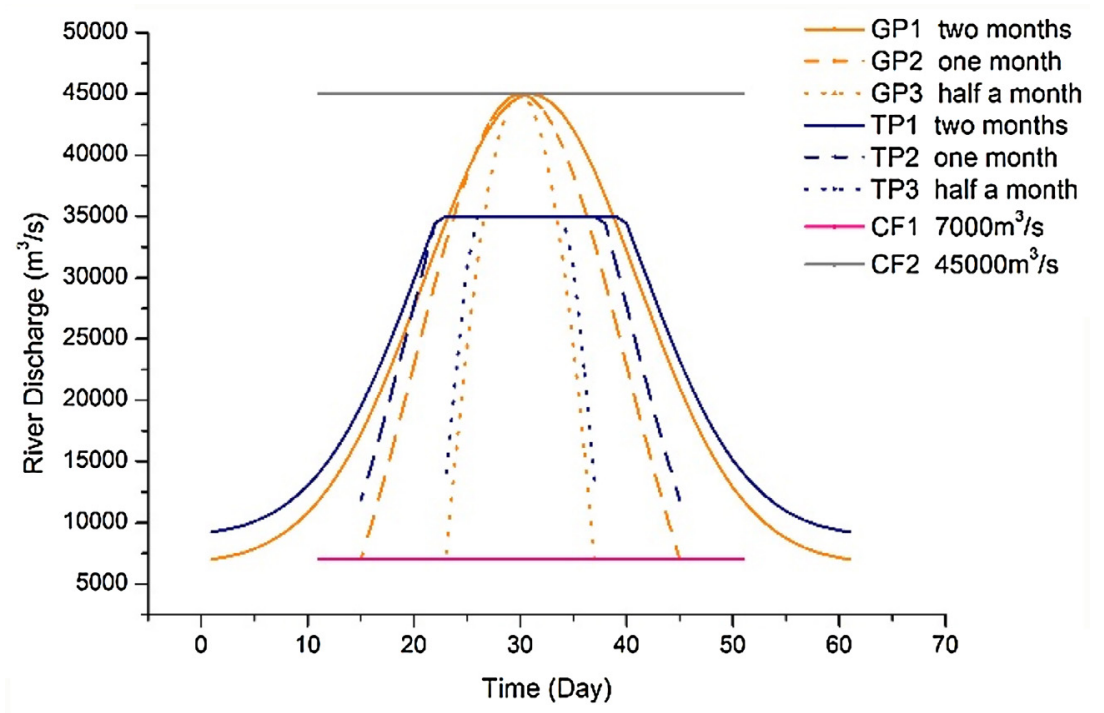

Fig. 4. Different types of freshwater pulse.

potential habitat aggregation during the critical season for Chinese mitten crab spawning.

\section{Discussion}

In the present study, we developed an approach to assessing effects of the freshwater pulse type in estuaries on the dispersal of species among fragmented habitat patches. Based on the mapped spatial patterns of suitable habitats for typical species, we developed an individual-based model to simulate how individuals disperse among fragmented habitat patches. The responses in species distributions to different hydrological pulses were then determined. We compared the simulated distribution of mitten crab in the case study area of the Yangtze River Estuary with a field survey performed by Jiang (2014) in Fig. 7. The comparison indicates that our simulated results were generally consistent with the identified spawning sites. In this case study, a Gaussian pulse from $7000-45,000 \mathrm{~m}^{3} / \mathrm{s}$ that lasts two months was recommended for the Yangtze River Estuary. This pulse would provide a win-win situation in regards to the occupancy of suitable habitat patches by individual organisms and the HAI.

Here, the requirements of the Chinese mitten crab for water depth, salinity, and salinity fluctuation rate were the focus of 


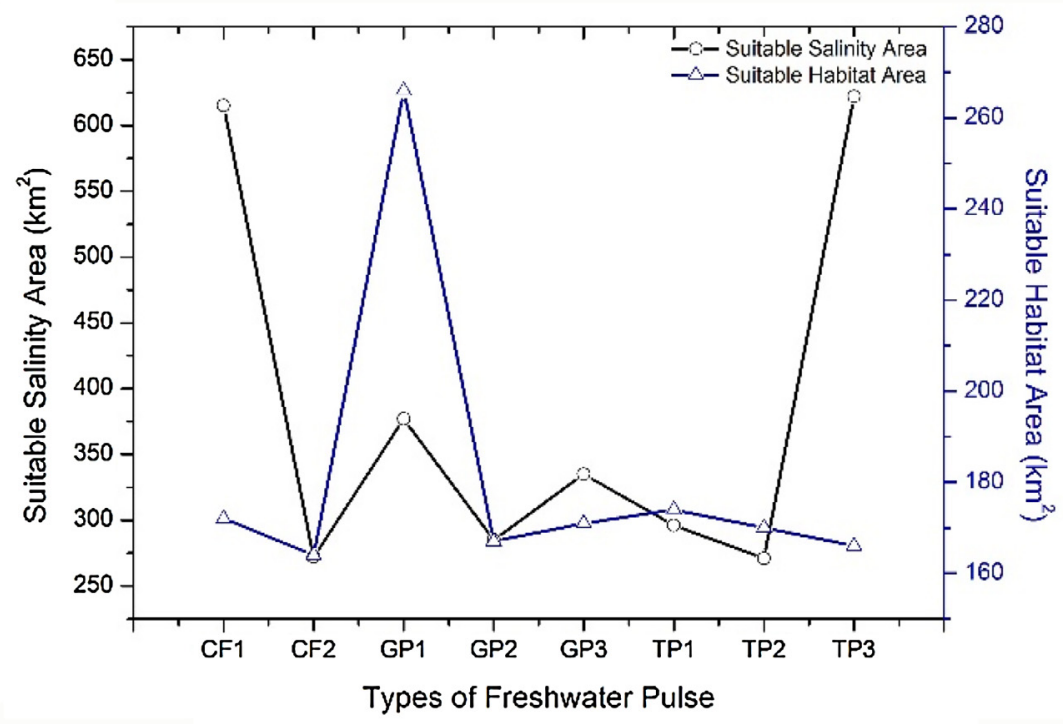

Fig. 5. Relationship between suitable salinity area and suitable habitat area with varying types of freshwater pulse.

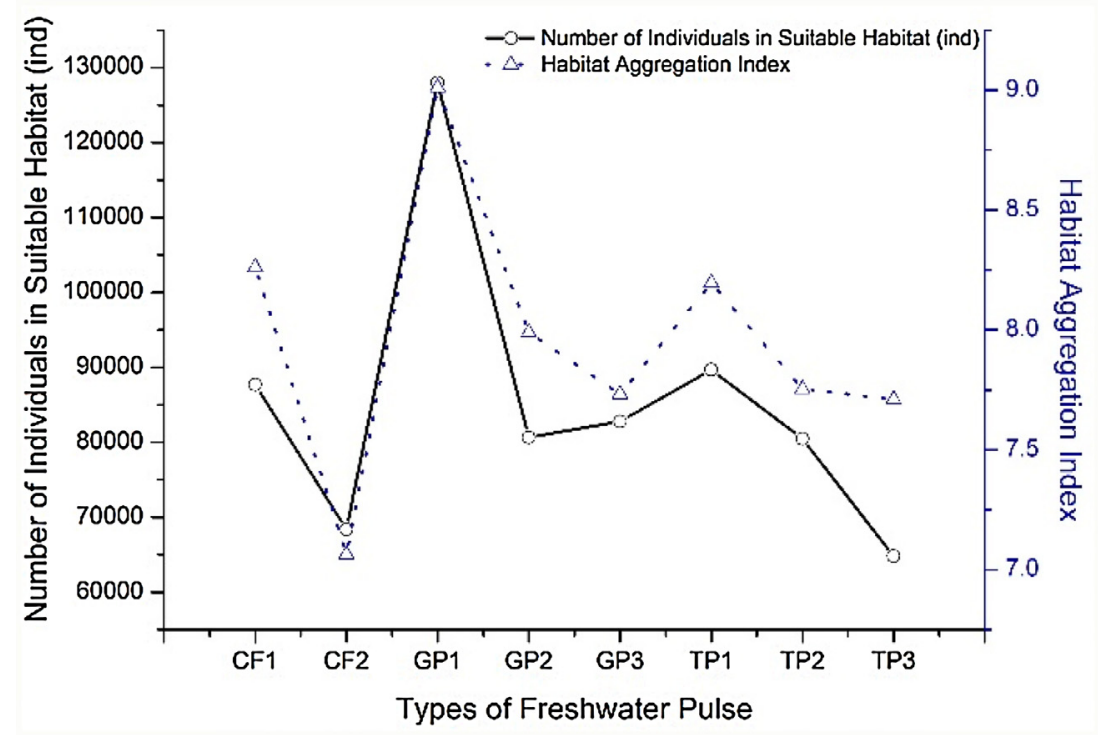

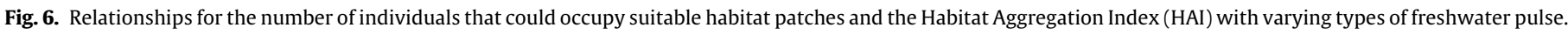

our environmental flow assessment. The approach we proposed is flexible. When additional species or environmental factors are involved in the assessment presented in Section 2.1, different types of freshwater pulse may be recommended to satisfy the diverse requirements of species at different scales (Sun et al., 2015). More importantly, we focused on the dispersal of species among fragmented habitat patches with altered hydrological processes. Based on the different levels of salinity objectives for habitat ecosystem health and the relationship between salinity and freshwater inflows, Zhao et al. (2009) recommend freshwater inflows of $938.2 \times 10^{9}, 729.4 \times 10^{9}$, or $615.5 \times 10^{9} \mathrm{~m}^{3} /$ year for the Yangtze River Estuary to satisfy a minimum, medium, or high level of habitat ecosystem health, respectively. Rather than defining environmental flows based on typical objectives, the present approach considered the diversity requirements of potential habitats for target species, and the type of freshwater pulse was assessed, rather than the average quantity or range of river discharge.
Through the storage and release activities at the Three Gorges Dam, the annual distributions of natural hydrological processes have been greatly altered (Yi et al., 2010), as manifested in both reductions of the peak flow and altered pulse durations. Fig. 8 illustrates the distributions of water salinity for different types of freshwater pulse. Variations in the freshwater pulse could affect the positions of a low salinity zone apparent in the Yangtze River Estuary. Under the action of a low constant flow of $7000 \mathrm{~m}^{3} / \mathrm{s}$ (CF1), the area at the end of the north branch would be dominated by tidal effects, which might cause seawater intrusion in this area. With an increase of peak flow and pulse duration, the isocline of low salinity (2 ppt) moved seaward, and seawater intrusion could be attenuated. Through a comparison of GP1, GP3, and TP1 in Fig. 8, we discovered that, without sufficient peak flow and pulse duration, GP3 and TP1 would cause a reduction in the suitable salinity area for Chinese mitten crabs in the south branch of Yangtze River Estuary. 


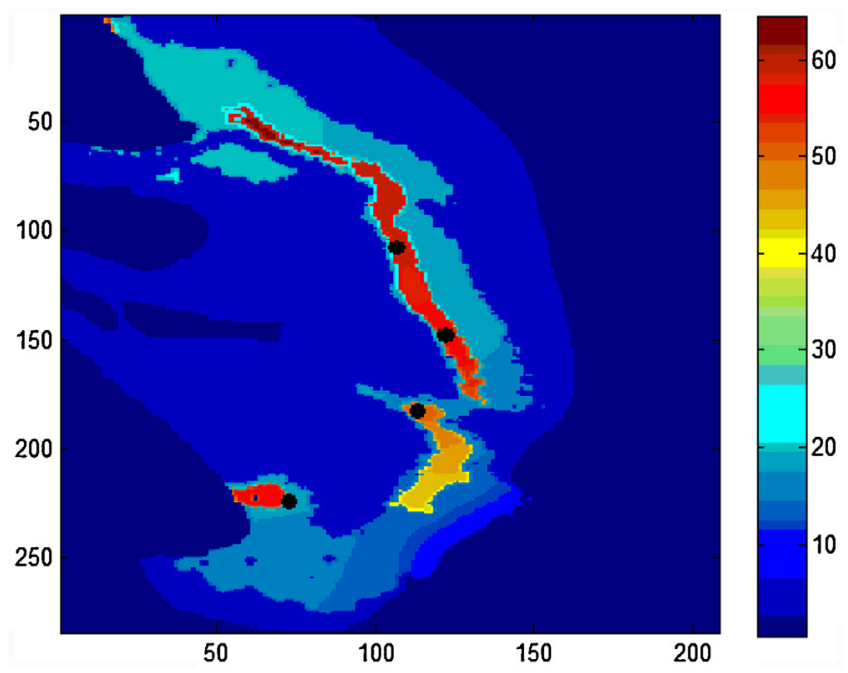

Fig. 7. Comparison of the simulated distribution of Chinese mitten crab during spawning season with spawning sites as identified by a field survey (black points).

Based on the results in Fig. 5, we did not detect a coincidence between the highest level of suitable salinity area and suitable habitat area with same type of freshwater pulse. Large areas of suitable salinity occurred at the end of the north branch under the action of $\mathrm{CF} 1$. However, the water depth and fluctuation rate were not suitable for the Chinese mitten crab. With GP1, the freshwater pulse could push the isocline of low salinity ( $8-15 \mathrm{ppt}$ ) to areas that have a suitable water depth and fluctuation rate, especially in areas at the end of the south branch (Fig. 9).

Fig. 10 presents a comparison between the distributions of potential suitable habitat (a) and the final distribution of Chinese mitten crabs after dispersal (b) for different types of freshwater pule. Potential habitats at the end of the south branch were more fragmented, especially for GP3 and TP1. Individual organisms preferred to disperse to the suitable habitat patches at the end of the north branch and the north passage of the south branch, which have high connectivity in the Yangtze River Estuary. Severe habitat fragmentation could obstruct species dispersal and ultimately affect the occupancy of suitable habitat by individual organisms. Similar results have also been found in other coastal areas for different species. A field survey experiment conducted in the Caribbean island of Aruba indicated that when the spatial distribution of coral reefs were a long distance from seagrass and mangroves, juvenile reef fish preferred seagrass and mangrove habitats, but did not have a clear preference when connectivity of these three habitats increased (Dorenbosch et al., 2007). However, with GP1, which generated large areas of continuous suitable habitat at the end of the south passage, there were also fewer individual organisms in the area. An important reason for this phenomenon might be that the suitable habitat patches were too far removed from the upstream origins of the species. The long dispersal distance could increase the amount of time and energy spent on movement, consequently increasing the risk of death and injury in the dispersal process (Bonte et al., 2012). From a cost minimization standpoint, individual organisms preferred closer habitats.

\section{Acknowledgements}

This work was supported by National Basic Research Program of China (973) (2013CB430402), the National Science Foundation for Innovative Research Group (No. 51121003), the National Natural Science Foundation of China (No. 51279007), and the Fundamental Research Funds for the Central Universities.
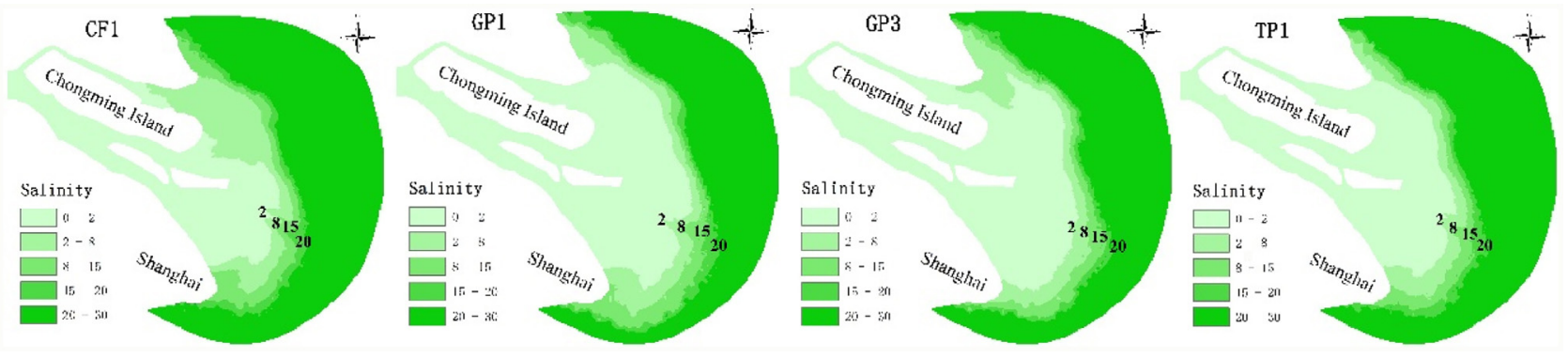

Fig. 8. Distributions of salinity for different types of freshwater pulse.
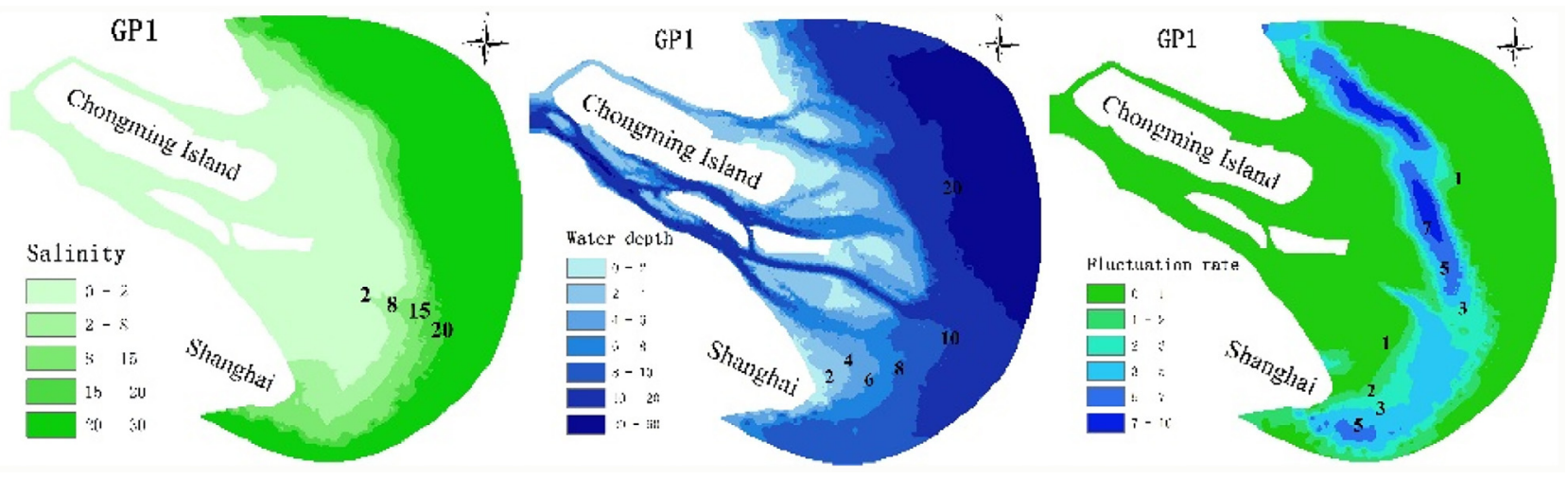

Fig. 9. Distributions of salinity, water depth, and fluctuation rate for Gaussian pulse 1. 

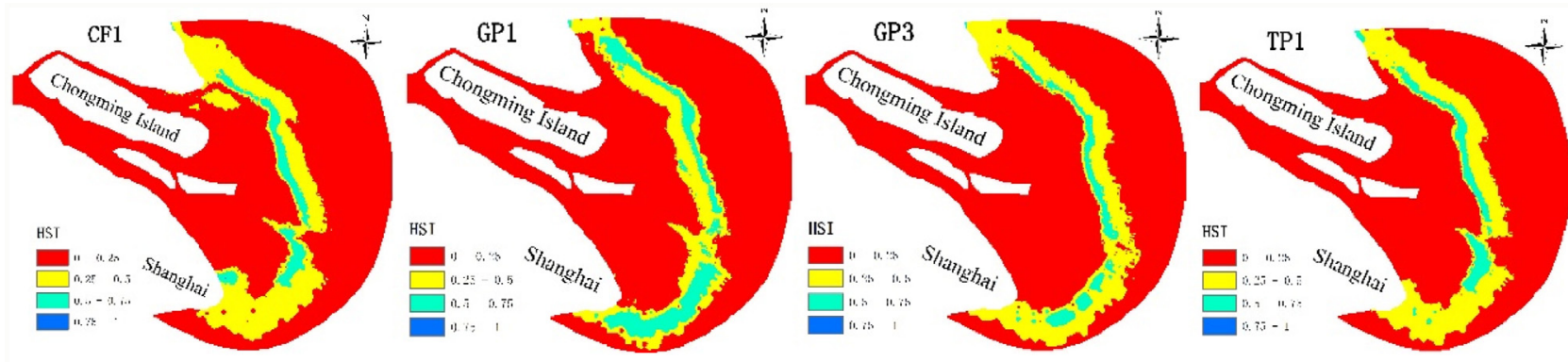

(a)
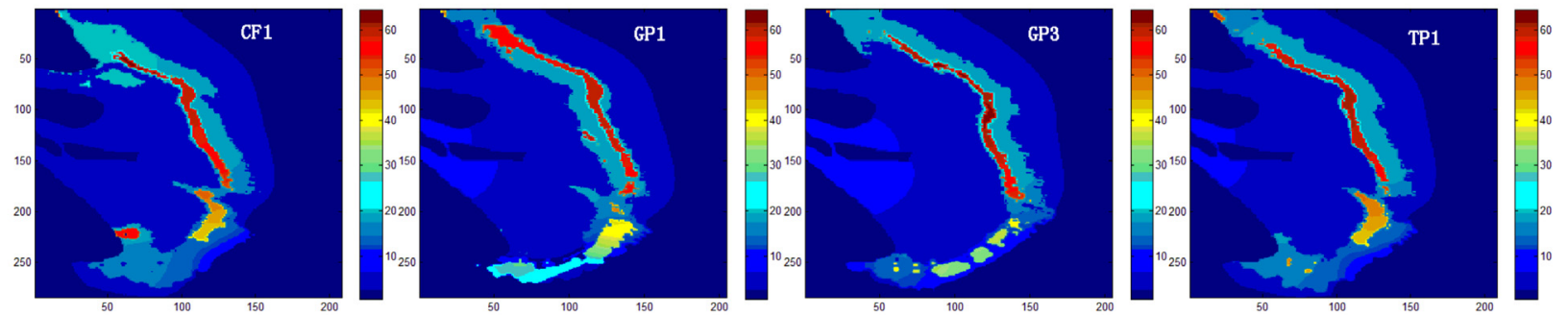

(b)

Fig. 10. (a) Distributions of potential suitable habitat and (b) distributions of Chinese mitten crab after dispersal.

\section{References}

Allison, M.A., Meselhe, E.A., 2010. The use of large water and sediment diversions in the lower Mississippi River (Louisiana) for coastal restoration. J. Hydrol. 387 (3), 346-360.

Antongiovanni, M., Metzger, J.P., 2005. Influence of matrix habitats on the occurrence of insectivorous bird species in Amazonian forest fragments. Biol. Conserv. 122 (3), 441-451.

Barnes, T.K., Mazzotti, F.J., Pearlstine, L.G., Volety, A.K., 2006. Habitat evaluation in coastal southwestern florida: a policy decision model for the blue crab, Callinectes sapidus. Florida Sci. 69, 140.

Bianchi, T.S., Allison, M.A., 2009. Large-river delta-front estuaries as natural recorders of global environmental change. Proc. Natl. Acad. Sci. 106 (20), 8085-8092.

Bierregaardet Jr, R.O., Lovejoy, T.E., Kapos, V., et al., 1992. The biological dynamics of tropical rainforest fragments. Bioscience 42, 859-866.

Bocedi, G., Zurell, D., Reineking, B., Travis, J.M., 2014. Mechanistic modelling of animal dispersal offers new insights into range expansion dynamics across fragmented landscapes. Ecography 37 (12), 1240-1253.

Bonte, D., Van Dyck, H., Bullock, J.M., et al., 2012. Costs of dispersal. Biol. Rev. 87, 290-312.

Browne, R.A., Wanigasekera, G., 2000. Combined effects of salinity and temperature on survival and reproduction of five species of Artemia. J. Exp. Mar. Biol. Ecol. 244 (1), 29-44.

Brush, J.M., Schwarzer, A.C., Frederick, P.C., 2016. Importance and function of foraging and roost habitat for wintering american oystercatchers. Estuaries Coasts, $1-10$.

Calliari, D., Borg, M.C.A., Thor, P., Gorokhova, E., Tiselius, P., 2008. Instantaneous salinity reductions affect the survival and feeding rates of the co-occurring copepods Acartia tonsa Dana and A. clausi Giesbrecht differently. J. Exp. Mar. Biol. Ecol. 362 (1), 18-25.

Cheng, Y.X., 1997. Effects of the Ambient Salinity on the Survival and Growth of Eriocheir Sinensis (China)

Crump, B.C., Hopkinson, C.S., Sogin, M.L., et al., 2004. Microbial biogeography along an estuarine salinity gradient: combined influences of bacterial growth and residence time. Appl. Environ. Microbiol. 70 (3), 1494-1505.

Cruzeiro, C., Rocha, E., Pardal, M.Â., et al., 2016. Environmental assessment of pesticides in the Mondego River Estuary (Portugal). Mar. Pollut. Bull. 103 (1), 240-246.

Döll, P., Fiedler, K., Zhang, J., 2009. Global-scale analysis of river flow alterations due to water withdrawals and reservoirs. Hydrol. Earth Syst. Sci. 13, 2413-2432.

Dorchin, A., Filin, I., Izhaki, I., et al., 2013. Movement patterns of solitary bees in a threatened fragmented habitat. Apidologie 44 (1), 90-99.

Dorenbosch, M., Verberk, W.C.E.P., Nagelkerken, I., van der Velde, G., 2007. Influence of habitat configuration on connectivity between fish assemblages of Caribbean seagrass beds, mangroves and coral reefs. Mar. Ecol. Prog. Ser. 334, 103-116.
Dover, J., Settele, J., 2009. The influences of landscape structure on butterfly distribution and movement: a review. J. Insect Conserv. 13 (1), 3-27.

Duan, X., Liu, S., Huang, M., Qiu, S., Li, Z., Wang, K., Chen, D., 2009. Changes in abundance of larvae of the four domestic Chinese carps in the middle reach of the Yangtze River, China, before and after closing of the Three Gorges Dam. Environ. Biol. Fishes 86 (1), 13-22.

Elgar, M.A., Clode, D., 2001. Inbreeding and extinctions in island populations: a cautionary tale. Conserv. Biol. 15, 284-286.

Fahrig, L., 2003. Effects of habitat fragmentation on biodiversity. Ann. Rev. Ecol Evol. Syst., 487-515.

Gallardo, B., García, M., Cabezas, Á., et al., 2008. Macroinvertebrate patterns along environmental gradients and hydrological connectivity within a regulated river-floodplain. Aquat. Sci. 70 (3), 248-258.

Guo, H., Hu, Q., Zhang, Q., et al., 2012. Effects of the three gorges dam on Yangtze River flow and river interaction with Poyang Lake, China: 2003-2008. J. Hydrol. 416, 19-27.

Heiler, G., Hein, T., Schiemer, F., et al., 1995. Hydrological connectivity and flood pulses as the central aspects for the integrity of a river-floodplain system. Regul. Rivers: Res. Manage. 11 (3-4), 351-361.

Inglis, G.J., Hurren, H., Oldman, J., Haskew, R., 2006. Using habitat suitability index and particle dispersion models for early detection of marine invaders. Ecol. Appl. 16 (4), 1377-1390

Jassby, A.D., Kimmer, W.J., Monismith, S.G., Arbor, C., Cloern, J.E., Powell, T.M. Schubel, B.W., ndVendlinski, T.J., 1995. Isohaline position as a habitat indicator for estuarine populations. Ecol. Appl. 5, 272-289.

Jiang, J.P., 2014. The Distributional Features of the Spawning Ground of Eriocheir Sinensis and Correlation to Major Environmental Factors in Yangtze River Estuary. China.

Kang, B.S., Park, H.B., Kim, J.K., 2015. Saltwater intrusion characteristics in seomjin river estuary using EFDC. J. Fish. Mar. Sci. Educ. 27 (6), 1842-1853.

Koch, E.W., 2001. Beyond light: physical, geological, and geochemical parameters as possible submersed aquatic vegetation habitat requirements. Estuaries 24 (1), 1-17.

Korus, J.T., Fielding, C.R., 2015. Asymmetry in Holocene river deltas Patterns, controls, and stratigraphic effects. Earth Sci. Rev. 150, 219-242.

Kun, Á., Scheuring, I., 2006. The evolution of density-dependent dispersal in a noisy spatial population model. Oikos 115 (2), 308-320.

Kurup, G.R., Hamilton, D.P., Patterson, J.C., 1998. Modelling the effect of seasonal flow variations on the position of salt wedge in a microtidal estuary. Estuar. Coast. Shelf S. 47 (2), 191-208.

Lamberth, S.J., Drapeau, L., Branch, G.M., 2009. The effects of altered freshwater inflows on catch rates of non-estuarine-dependent fish in a multispecies nearshorelinefishery. Estuar. Coast. Shelf Sci. 84, 527-538.

Layman, C.A., Arrington, D.A., Langerhans, R.B., et al., 2004. 2004: Degree of fragmentation affects fish assemblage structure in Andros Island (Bahamas) estuaries. Caribb. J. Sci. 40 (2), 232-244.

Lees, A.C., Peres, C.A., 2009. Gap-crossing movements predict species occupancy in Amazonian forest fragments. Oikos 118 (2), 280-290. 
Lefcheck, J.S., Marion, S.R., Lombana, A.V., et al., 2016. Faunal communities are invariant to fragmentation in experimental seagrass landscapes. PLoS One 11 (5), e0156550

Li, F., Cai, Q., Fu, X., et al., 2009. Construction of habitat suitability models (HSMs) for benthic macroinvertebrate and their applications to instream environmental flows: a case study in Xiangxi River of Three Gorges Reservior region, China. Prog. Nat. Sci. 19 (3), 359-367.

Lindenmayer, D.B., Fischer, J., 2013. Habitat Fragmentation and Landscape Change: an Ecological and Conservation Synthesis. Island Press.

Liu, Z., Hashim, N.B., Kingery, W.L., et al., 2008. Hydrodynamic modeling of St. Louis Bay estuary and watershed using EFDC and HSPF. J. Coast. Res., 107-116.

Liu, J.T., Hsu, R.T., Hung, J.J., et al., 2016. From the highest to the deepest: the Gaoping River-Gaoping Submarine Canyon dispersal system. Earth Sci. Rev. 153, 274-300.

Lotze, H.K., Lenihan, H.S., Bourque, B.J., et al., 2006. Depletion, degradation, and recovery potential of estuaries and coastal seas. Science 312 (5781), 1806-1809.

Lytle, D.A., Poff, N.L.R., 2004. Adaptation to natural flow regimes. Trends Ecol. Evol. 19 (2), 94-100.

Mueller, B., Ber, M., Yao, Z.P., et al., 2008. How polluted is the yangtze river? water quality downstream from the three gorges dam. Sci. Total Environ. 402 (2), 232-247.

Piehler, M.F., Smyth, A.R., 2011. Habitat-specific distinctions in estuarine denitrification affect both ecosystem function and services. Ecosphere 2 (1), $1-17$

Pringle, C.M., 2001. Hydrologic connectivity and the management of biological reserves: a global perspective. Ecol. Appl. 11 (4), 981-998.

Rabinowitz, A., Zeller, K.A.A., 2010. Range-wide model of landscape connectivity and conservation for the jaguar, Panthera onca. Biol. Conserv. 143 (4) 939-945.

Robins, J.B., Halliday, I.A., Staunton-Smith, J., Mayer, D.G., Sellin, M.J., 2005. Freshwater-flow requirements of estuarine fisheries in tropical Australia: a review of the state of knowledge and application of a suggested approach. Mar. Freshw. Res. 56 (3), 343-360.

Roy, P.S., Williams, R.J., Jones, A.R., et al., 2001. Structure and function of south-east Australian estuaries Estuarine. Coast. Shelf Sci. 53 (3), 351-384.

Rudnick, D., Veldhuizen, T., Tullis, R., Culver, C., Hieb, K., Tsukimura, B., 2005. A life history model for the San Francisco Estuary population of the Chinese mitten crab, Eriocheir sinensis (Decapoda: grapsoidea). Biol. Invasions 7 (2), 333-350.

Seo, D.G., Ahn, J.H., 2012. Prediction of chlorophyll-a changes due to weir constructions in the Nakdong River using EFDC-WASP modeling. Environ. Eng. Res. 17 (2), 95-102.
Sun, T., Xu, J., Yang, Z.F., 2013. Environmental flow assessments in estuaries based on an integrated multi-objective method. Hydrol. Earth Syst. Sci. 17 (2), $751-760$.

Sun, T., Zhang, H., Yang, Z., et al., 2015. Environmental flow assessments for transformed estuaries. J. Hydrol. 520, 75-84.

Tharme, R.E., 2003. A global perspective on environmental flow assessment: emerging trends in the development and application of environmental flow methodologies for rivers. River Res. Appl. 19 (5-6), 397-441.

Thrush, S.F., Halliday, J., Hewitt, J.E., et al., 2008. The effects of habitat loss: fragmentation, and community homogenization on resilience in estuaries. Ecol. Appl. 18 (1), 12-21.

Tullos, D., 2009. Assessing the influence of environmental impact assessments on science and policy: an analysis of the Three Gorges Project. J. Environ. Manage. 90, S208-S223.

Valdemarsen, T., Quintana, C.O., Flindt, M.R., et al., 2015. Organic N and P in eutrophic fjord sediments-rates of mineralization and consequences for internal nutrient loading. Biogeosciences 12 (6), 1765-1779.

Walsh, C.T., Reinfelds, I.V., Ives, M.C., et al., 2013. Environmental influences on the spatial ecology and spawning behaviour of an estuarine-resident fish, Macquaria colonorum Estuarine. Coast. Shelf Sci. 118, 60-71.

Wang, R.F., 2012. Physical and Behavioral Response of Eriocheir Sinensis Brood Stock, Early Developmental Stages to Salinity (China).

Xu, X., Tan, Y., Yang, G., 2013. Environmental impact assessments of the Three Gorges Project in China: issues and interventions. Earth Sci. Rev. 124, 115-125.

Xue, S., Sun, T., Zhang, H., et al., 2016. Suitable habitat mapping in the Yangtze River Estuary influenced by land reclamations. Ecol. Eng. 97, 64-73.

Yang, Z.F., Sun, T., Cui, B.S., et al., 2009. Environmental flow requirements for integrated water resources allocation in the Yellow River Basin, China. Commun. Nonlin. Sci. Numer. Simul. 14 (5), 2469-2481.

Yang, Z., Wang, T., Voisin, N., et al., 2015. Estuarine response to river flow and sea-level rise under future climate change and human development Estuarine. Coast. Shelf Sci. 156, 19-30.

Yi, Y., Wang, Z., Yang, Z., 2010. Impact of the Gezhouba and Three Gorges Dams on habitat suitability of carps in the Yangtze River. J. Hydrol. 387 (3), 283-291.

Young, A., Boyle, T., Brown, T., 1996. The population genetic consequences of habitat fragmentation for plants. Trends Ecol. Evol. 11 (10), 413-418.

Zhang, H.Y., Sun, T., Yang, W., Shao, D.D., 2016. Fuzzy logic method for evaluating habitat suitability in an estuary affected by land reclamation. Wetlands 36 , S19-S30.

Zhao, R., Yang, Z.F., Sun, T., Chen, B., Chen, G.Q., 2009. Freshwater inflow requirements for the protection of the critical habitat and the drinking water sources in the Yangtze River Estuary, China. Commun. Nonlin. Sci. Numer. Simul. 14 (5), 2507-2518. 